\title{
BMJ Open Patient-rated importance of key information on screening colonoscopy in Germany: a survey of statutory health insurance members
}

To cite: Dreier M, Krueger K, Walter U. Patient-rated importance of key information on screening colonoscopy in Germany: a survey of statutory health insurance members. BMJ Open 2018;8:e019127. doi:10.1136/ bmjopen-2017-019127

- Prepublication history for this paper is available online. To view these files, please visit the journal online (http://dx.doi. org/10.1136/bmjopen-2017019127).

Received 11 August 2017

Revised 24 April 2018

Accepted 8 June 2018
Check for updates

(c) Author(s) (or their employer(s)) 2018. Re-use permitted under CC BY-NC. No commercial re-use. See rights and permissions. Published by BMJ.

Institute of Epidemiology, Social Medicine and Health System Research, Hannover Medical School, Hannover, Germany

Correspondence to

Dr Maren Dreier;

dreier.maren@mh-hannover.de

\section{ABSTRACT}

Background Primary colonoscopic screening is considered to be of great benefit but also has the potential to cause severe harm. Thus, eligible subjects should be supported in making an informed choice whether to participate.

Objectives To identify information on screening colonoscopy that colonoscopy-naïve subjects rate as particularly important for decision making.

Design Survey of German statutory health insurance members using a written questionnaire in November 2015. Study population Colonoscopy-naïve individuals aged 50 to 65 years.

Main outcome measures Importance of key information about screening colonoscopy, including potential risks and benefits, baseline risk of colorectal cancer/polyps and practical aspects of the procedure, as well as associations between participants' characteristics and their judgement of information as to being 'very important'.

Results Of 1871 respondents (overall response rate: $31 \%$ ), a subgroup of 370 colonoscopy-naïve subjects was eligible for inclusion (average age: 55 years, $47 \%$ male). Information on the risks was rated as very important by most respondents, unimportant by $6 \%$. Information on the benefits was considered unimportant by $26 \%$. Regression analysis showed that less educated persons regarded most items to be more often relevant than highly educated subjects. A greater proportion of women than men rated details regarding pain and practical aspects as very important. Subjects with a low educational level living alone were identified as the group with the least interest in information on risks.

Conclusion Cultivating awareness around the central meaning of the (quantitative) benefits of screening in informed decision making should be focused on more in future information materials. The high requirement of less educated people to become more informed provides a strong motivation for further efforts to develop evidencebased information that adequately informs this group. Tailoring information according to gender-specific needs may be warranted in light of the observed differences in information preferences between women and men.

\section{INTRODUCTION}

Colorectal cancer (CRC) is one of the most common cancers, accountable for one-third

\section{Strength and limitations of this study}

- This study provides a unique insight into the perceived importance of key informational needs in regards to screening colonoscopy as reported by colonoscopy-naïve persons themselves.

- Multivariable analyses adjusted for several potentially associated factors enhance the validity of the results.

- The study population included members of a single German statutory health insurance company; however, as $85 \%$ of Germans are covered by statutory health insurances, and German residents are largely free to choose between companies, all of which offer very similar benefits and competitive prices, our results are likely generalisable among all German residents.

of all newly diagnosed cases of cancer and $25 \%$ of all cancer-related deaths worldwide. ${ }^{1}$ Since colonoscopy has a high accuracy rate for detecting CRC, CRC is nonetheless probably one of the best screenable cancer diseases. Moreover, endoscopic procedures have the potential to reduce CRC mortality and CRC incidences. ${ }^{2}$ However, their benefits are also associated with adverse events such as bleeding ( 5 in 10000 ), perforation ( 8 in $10000)$ or even death in very rare cases. ${ }^{34}$

Considering these risks, the question of whether to go to CRC screenings and which test to undergo outlines a very preference-sensitive decision. Persons eligible for CRC screening should be able to make an informed decision based on knowledge about the specific benefits and risks of the procedure, including quantitative information, in order to realise their extent in absolute frequencies, and individual values. ${ }^{5-7}$ In recent years, the demand for evidence-based, balanced, neutral information to support informed decision making has been increasingly included in cancer screening guidelines. ${ }^{89}$ Germany will thus initiate a legally 
defined CRC screening programme with screening information letters, including explicit information on the benefits and risks of the procedure in order to enable patients to make an informed decision for or against CRC screening. ${ }^{10}$ The faecal immunochemical testing and colonoscopy are currently the only two CRC screening tests covered under statutory insurance plans in Germany without additional payment. Since October 2002, insurees aged 55 years and older have been eligible to receive a colonoscopy for primary screening once every 10 years. ${ }^{3}$ Primary screening colonoscopy is currently offered in Austria, the Czech Republic, Poland, Switzerland and the USA. ${ }^{11}$

Evidence-based health education often includes extensive information, even though brief information may be more appropriate for some target groups and situations. The prioritisation of content is essential for providing short summaries such as option grids. ${ }^{12}$ Following a patient-centred strategy, we explored the information needs of subjects currently entitled to attend CRC screenings or who will be in the future. Our focus was on colonoscopy because of its greater benefits and higher risk potential,${ }^{13}$ with our goal being to systematically collect detailed data on which specific information about colonoscopy subjects with no history of colonoscopy considered important and relevant and to identify any potential variations between different groups in the study population. Colonoscopy-naïve subjects were chosen, because having experienced a colonoscopy may affect the subject's importance ratings. The results of this cross-sectional survey may contribute to the patient-centred development and the revision of evidence-based decision aids on CRC screenings, including information tailored to the informational needs of individual target groups.

\section{METHODS}

\section{Study design and setting}

In November 2015, randomly selected members of a large German statutory health insurance company (Barmer GEK, 8.5 million members) were sent a questionnaire survey on colonoscopy experience and information needs of subjects with and without a previous history of colonoscopy. A total of 2011579 women and men aged 50-65 years were eligible. The random sample was stratified by age, sex and colonoscopy status to account for higher expected response rates in subjects with a history of colonoscopy (same proportions in age groups $50-54 / 55-59 / 60-65$, and in women/men). The sample of 6000 individuals included subjects with a history of colonoscopy within the previous year, from April 2014 to March $2015(\mathrm{n}=2400)$ to minimise recall bias, as well as subjects with no documented history of a colonoscopy in the available period from January 2010 to March 2015 $(\mathrm{n}=3600)$ (figure 1).

To address the information needs of colonoscopy-naïve subjects, we included a subgroup in the whole survey population, that is, those participants with no documented or self-reported history of prior colonoscopies (figure 1). Subjects with a self-reported history of CRC were excluded, because they do not belong to the CRC screening target group composed only of people with an average CRC risk.

\section{Survey instrument}

The standardised questionnaire was sent to the selected members by the insurance company and could be returned to our research unit at Hannover Medical School. In order to minimise any inconvenience to their customers, the insurance company did not issue reminders. The first page described the colonoscopy procedure and provided a schematic drawing showing the colon and the endoscope. The questionnaire was in German and included 51 questions on the patients' prior history of colonoscopy, experiences with the latest colonoscopy, the importance of key information on the colonoscopic history of cancer and sociodemographic characteristics. To ensure comprehensibility, the questionnaire had been subjected to 10 cognitive pretests and modified accordingly. Participants of the pretests were 23-75 years old, among these were three experts, six females, five colonoscopy naïve and three less educated. Data on the importance of key information were collected in 15 questions covering the following four categories:

1. Potential benefits (three items: reduction of incidence, reduction of mortality, removal of polyps).

2. Risks and side effects (five items: risks present, frequency of risks, chances of overlooking CRC, pain and side effects of laxatives).

3. Baseline risk of CRC/polyps (two items: risk of disease next within the next 10 years and prevalence of polyps).

4. Practical aspects of the procedure (five items: laxative use, examination intervals, effect on driving ability, ability to work and sex of the endoscopist).

The chosen items were based on recommendations for evidence-based health information, ${ }^{5}$ prior evaluations ${ }^{14}$ and on a list of criteria for evaluating consumer education material on CRC screenings. ${ }^{15}$ The response options were included in a 4-point Likert scale with the categories: very important, moderately important, relatively unimportant and very unimportant. The English translations of the questions are shown in figure 2. Education levels were classified according to the date of the final examination: low (after grade 9), intermediate (after grade 10) or high (after grade 12 or 13). Persons not born in Germany or whose father or mother was not born in Germany were said to have a 'migrant background'. ${ }^{16}$ Health literacy was assessed using the validated screening question: "How confident are you filling out medical forms by yourself?'. ${ }^{17}$

\section{Data analysis}

Data were combined via a key variable with selected anonymous individual data from the insurance company. All data used for this analysis were derived 


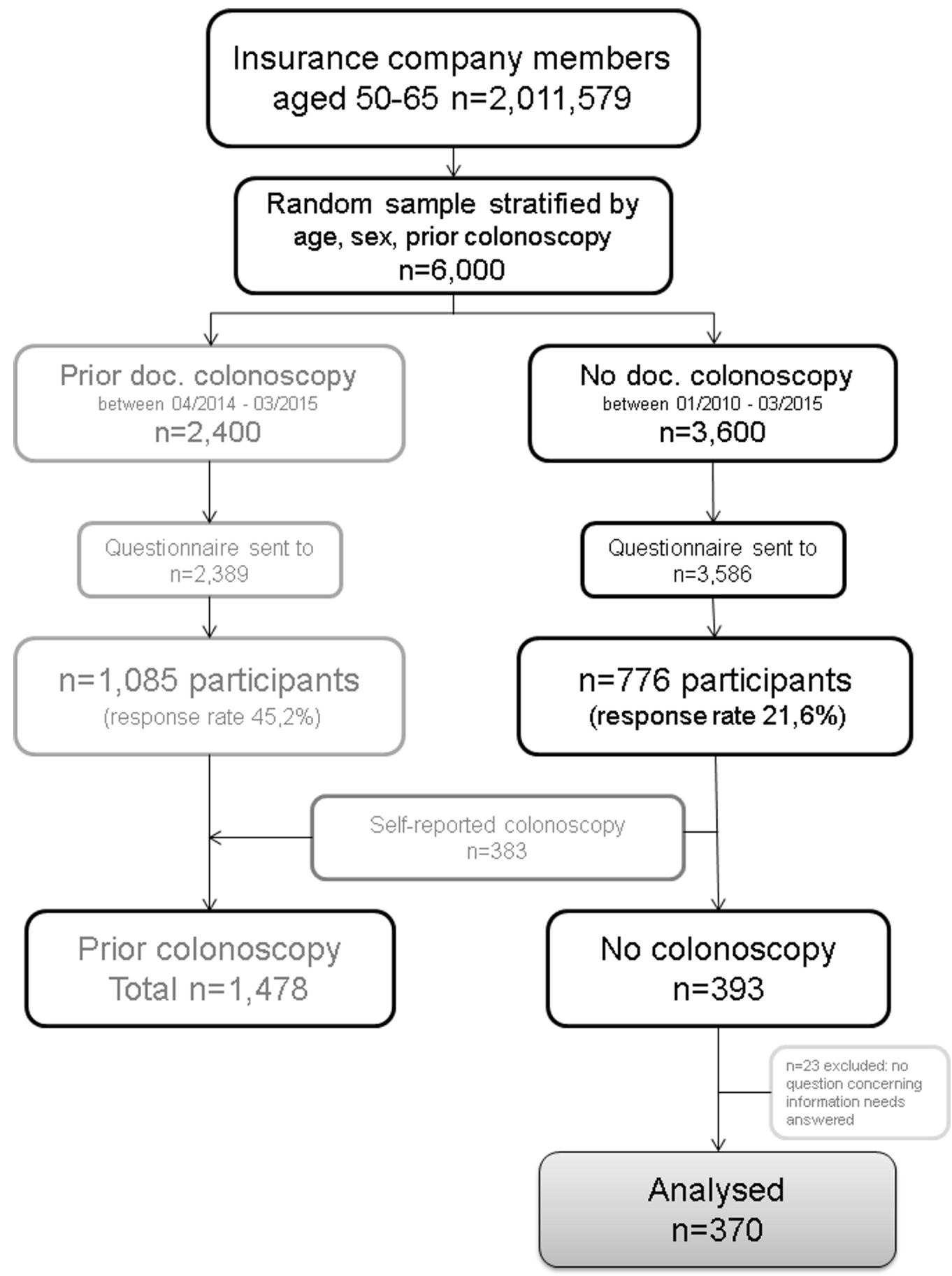

Figure 1 Flow chart of the study population.

from the questionnaire except the subjects' occupational statuses, which came from the insurance data set. Self-reported information on age, sex and prior colonoscopies was validated through comparison with the health insurance data. All analyses were performed using IBM SPSS Statistics, V.24. Frequency analyses and cross-tabulations were performed. Multivariable logistic regression modelling was performed to identify associations between the participants' characteristics and the outcomes/ ratings 'very important' versus 'other' for each of the 15 questions. The following variables were included: sex, age group, education, health literacy, self-reported health, household size, living in Eastern/ Western Germany and migrant background. The following interaction terms were tested: sex*education, sex*household size, sex*self-reported health and education*household size. Other interaction terms were not included due to the low numbers of single cells. Interaction terms shown to be associated with the outcome below $\mathrm{p}<0.25$ were included; otherwise, the number of terms would have been too high. All statistical tests were two sided. A p value less than 0.05 was considered statistically significant. 


\section{How important to you personally is the information on:}

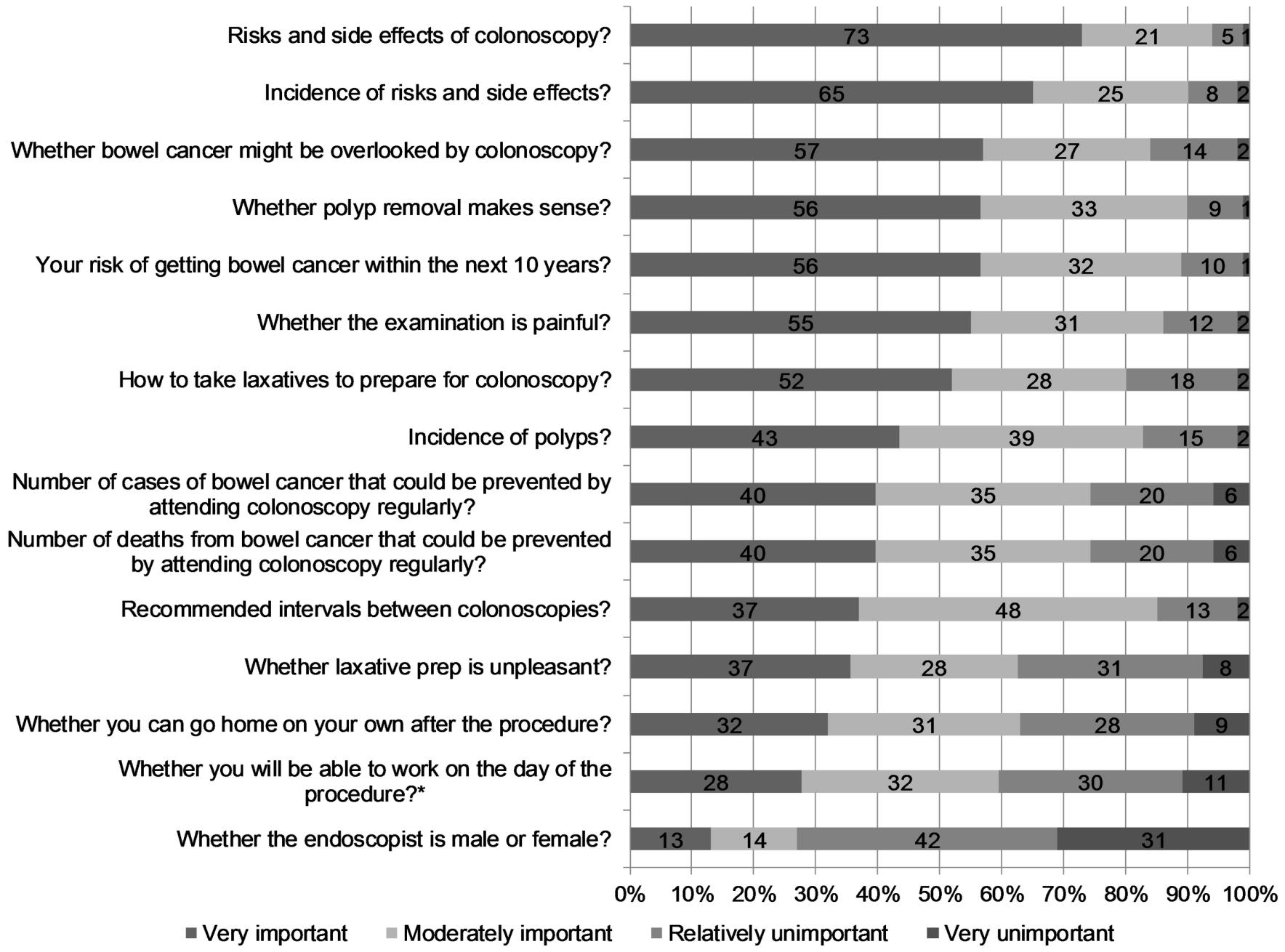

Figure 2 Importance of key information about screening colonoscopy ( $n=354-365)$. * Responses from employed persons only $(n=279)$.

\section{Response of the study population}

While the response rate of the whole survey population was $31.8 \%$ (figure 1), the proportion of persons without a prior colonoscopy in relation to the whole survey population was unclear as information on documented prior colonoscopies from the insurance data was restricted to the period January 2010 to March 2015. Information on whether the participants had a prior colonoscopy or were colonoscopy naïve was derived from documented and self-reported colonoscopy, the latter was necessary to cover the period before 2010, as well as between April 2015 and the time of the survey. From the preselected insurees without a documented colonoscopy $(n=3600)$, $21.6 \%(\mathrm{n}=776)$ responded, half thereof reported a prior colonoscopy. The number of subjects within the initially preselected 3600 insurees without a prior colonoscopy was unknown as the actual colonoscopic status of non-responders remained unknown due to the missing self-reported statuses. For this reason, it was impossible to calculate a response rate or to do a non-responder analysis. However, the best option for a group comparison was to include the initial preselected 3600 insurees with no documented colonoscopy in the non-responder analysis and thereby compare available data from the insurance company (age, sex and 5-year uptake of a biannually offered health check-up).

\section{Ethical consideration}

The study protocol was approved by the ethics committee of Hannover Medical School (application no. 29182015). The study was conducted in cooperation with the Bertelsmann Foundation (a non-profit organisation) and Barmer GEK, who paid for printing and postage of the questionnaires and for third-party data entry services. Barmer GEK sampled the study population according to our specifications and provided anonymous data on the study population. Precautions were taken to ensure that Barmer GEK could not deanonymise their members' questionnaires by sending the questionnaire back to us. The data entry service, to which we sent the questionnaire, was also not allowed to return data with IDs to Barmer GEK. The cooperation agreement ensured the authors' 
independence in designing the study, interpreting the data and writing and publishing the report.

\section{Patient and public involvement}

There were no individuals involved in the development of the research question, the design of the study or the recruitment to and conduct of the study. The research question was derived in the context of the future CRC screening programme in order to get deeper insights into the individual's preferences on evidencebased health information. The authors will communicate the findings through national conferences.

\section{RESULTS}

A total of 1871 (31.8\%) subjects completed the survey questionnaire. A subpopulation of 370 colonoscopy-naïve respondents was eligible for inclusion in this study (figure 1). The response rate of this subpopulation remained unknown due to an unknown denominator (the subgroup was based on criteria collected within the survey), which is explained in detail in the methods section. Comparison of the responders $(n=776) /$ non-responders $(n=3586)$ of the initially sampled subjects with no documented colonoscopy showed no relevant differences in the mean age (responder/non-responder: $57.9 / 57.2$ years) and proportion of sex $(47.9 / 50.6 \%)$ but indicated a slightly higher uptake of a health check-up in the responder group $(72 / 63 \%)$. As shown in table 1, the study population had an average age of 55 years, $47 \%$ were male and more than $40 \%$ were highly educated. The vast majority $(85 \%)$ perceived their health as good or better.

Most of the participants (60\%-93\%) rated the different items on screening information as moderately important or very important except for information on the sex of the endoscopist, which was important for only $27 \%$ (figure 2 ). Information on the types and frequencies of risks and side effects was most frequently rated as being important and not important by $6 \%$ and $10 \%$, respectively. Overall seven items covering the categories 'risks and side effects' (4 of 5 items), baseline risks ( 1 of 2 items), practical aspects ( 1 of 5 items) and benefits ( 1 of 3 items) were perceived as the most important issues (very important for at least $50 \%$ of the population) (figure 2). Key information on benefits, that is, on how many cases of CRC or CRC-related deaths could be prevented by screening, was rated as 'very important' by $40 \%$ of the participants and as either relatively or very unimportant by $26 \%$. Further analyses focus on the information rated as 'very important'.

Stratification by sex showed some variations in the 'very important' ratings. Women rated information as very important more often than men (figure 3). The biggest differences were seen in regard to risks, pain, laxative use and going home independently afterwards. Conversely, quantitative information on issues, like the frequency of risks and polyps and the number of lives saved and deaths prevented, seems to be equally important for both sexes.
Table 1 Characteristics of the study population $(n=370)$

\begin{tabular}{|c|c|c|c|}
\hline Characteristics & Categories & $\mathbf{n}$ & $\%$ \\
\hline \multirow[t]{3}{*}{ Age, years $(n=368)$} & $50-54$ & 162 & 44.0 \\
\hline & $55-59$ & 129 & 35.1 \\
\hline & $60-64$ & 77 & 20.9 \\
\hline \multirow[t]{2}{*}{$\operatorname{Sex}(n=368)$} & Male & 173 & 47.0 \\
\hline & Female & 195 & 53.0 \\
\hline \multirow[t]{3}{*}{ Education level $(n=362)$} & High & 152 & 41.1 \\
\hline & Intermediate & 133 & 36.7 \\
\hline & Low & 77 & 21.3 \\
\hline \multirow[t]{6}{*}{ Employment status $(n=325)$} & White-collar worker & 158 & 48.6 \\
\hline & Blue-collar worker & 61 & 18.8 \\
\hline & Unemployed & 24 & 7.4 \\
\hline & Retired & 38 & 11.7 \\
\hline & Self-employed & 29 & 8.9 \\
\hline & Other & 15 & 4.6 \\
\hline \multirow[t]{4}{*}{ Household size $(n=359)$} & One person & 51 & 14.2 \\
\hline & Two persons & 188 & 52.4 \\
\hline & Three persons & 64 & 17.8 \\
\hline & $>3$ persons & 56 & 15.6 \\
\hline \multirow{4}{*}{$\begin{array}{l}\text { City of residence, } \\
\text { inhabitants }(n=357)\end{array}$} & $<5000$ & 118 & 33.1 \\
\hline & $5000-20000$ & 77 & 20.8 \\
\hline & 20000-100000 & 81 & 22.7 \\
\hline & $>100000$ & 81 & 22.7 \\
\hline \multirow[t]{2}{*}{ Region $(n=362)$} & Eastern Germany & 94 & 26.0 \\
\hline & Western Germany & 268 & 74.0 \\
\hline $\begin{array}{l}\text { Migrant background } \\
(n=364)\end{array}$ & Yes & 40 & 11.0 \\
\hline \multirow{5}{*}{$\begin{array}{l}\text { Self-reported health } \\
(n=360)\end{array}$} & Excellent & 18 & 5.0 \\
\hline & Very good & 112 & 31.1 \\
\hline & Good & 183 & 50.8 \\
\hline & Not so good & 36 & 10.0 \\
\hline & Poor & 11 & 3.1 \\
\hline \multicolumn{4}{|l|}{ Health literacy $(n=362)$} \\
\hline & $\begin{array}{l}\text { Extremely or very } \\
\text { confident } \\
\text { Moderately/ } \\
\text { slightly or/not at all } \\
\text { confident }\end{array}$ & $\begin{array}{l}261 \\
101\end{array}$ & $\begin{array}{l}72.1 \\
27.9\end{array}$ \\
\hline History of cancer? $(n=365)$ & Yes & 26 & 7.1 \\
\hline $\begin{array}{l}\text { First-degree relatives with } \\
\text { colorectal cancer? }(n=365)\end{array}$ & Yes & 31 & 8.5 \\
\hline $\begin{array}{l}\text { Related persons with } \\
\text { cancer? }(n=365)\end{array}$ & Yes & 226 & 61.9 \\
\hline
\end{tabular}

The ratings varied substantially according to the educational level. Subjects with high education rated most of the information as being less important than those with lower levels of school education (figure 4). No significant educational differences were detected in regard to 


\section{How important to you personally is the information on:}

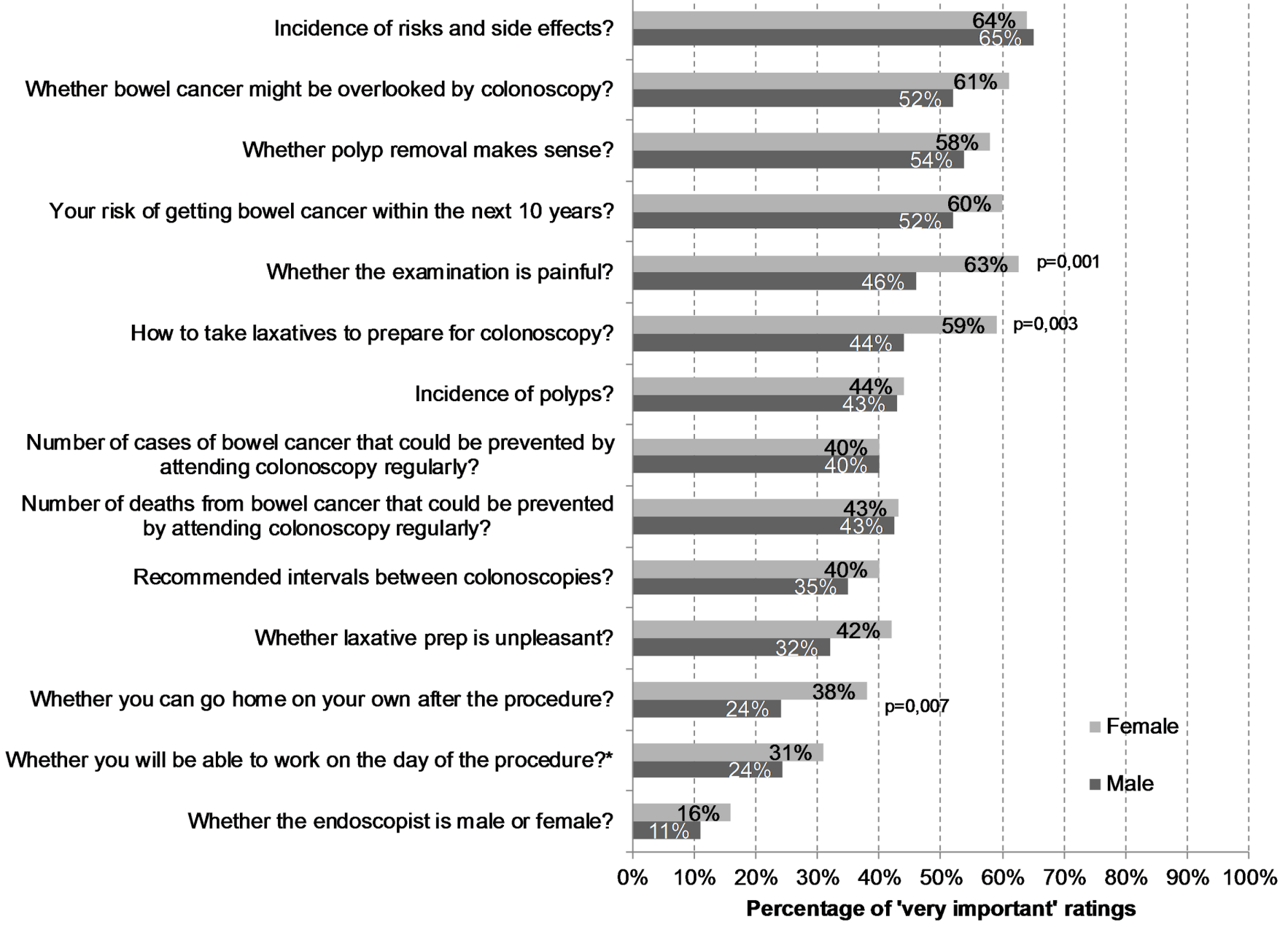

Figure 3 Importance of key information about screening in women and men ( $n=352-363)$. *Responses from employed persons only $(n=279)$.

information on the risks of colonoscopy $(\mathrm{p}=0.063)$ or the number of cases of CRC that could be prevented by colonoscopic screening $(\mathrm{p}=0.055)$. The absolute ranking on the percentage of very important information yielded very similar results across the different educational categories.

Multivariable logistic regression models produced very similar results to those of the stratified analyses showing that sex and education were the main factors associated with the importance ratings (table 2). Health literacy was not associated with importance ratings in the regression models. Deviating from the stratified analyses, the perceived importance of information on risks and side effects was higher than expected in the low education group compared with the high education group, while the intermediate education group considered information on the benefits (eg, the number of cases of bowel cancer or death that could be prevented) more often as very important than the high education group.
Subjects with a low educational level living alone (single household size) were significantly less interested in information on the types and frequencies of screening risks (see interaction terms in table 2). As the interpretation of results that include interaction terms may be difficult, we shall illustrate this interaction (figure 5). However, while the main direction is correctly represented in this figure, there may be slight differences to the multivariable association. Further stratification to characterise subjects with a low educational level living alone more accurately was not feasible due to the low number of subjects.

\section{DISCUSSION}

Our survey of the perceived needs for information on screening colonoscopy of 370 German insurees with no prior history of colonoscopy showed that the vast majority rated information on all but one item as being important. 
How important to you personally is the information on:

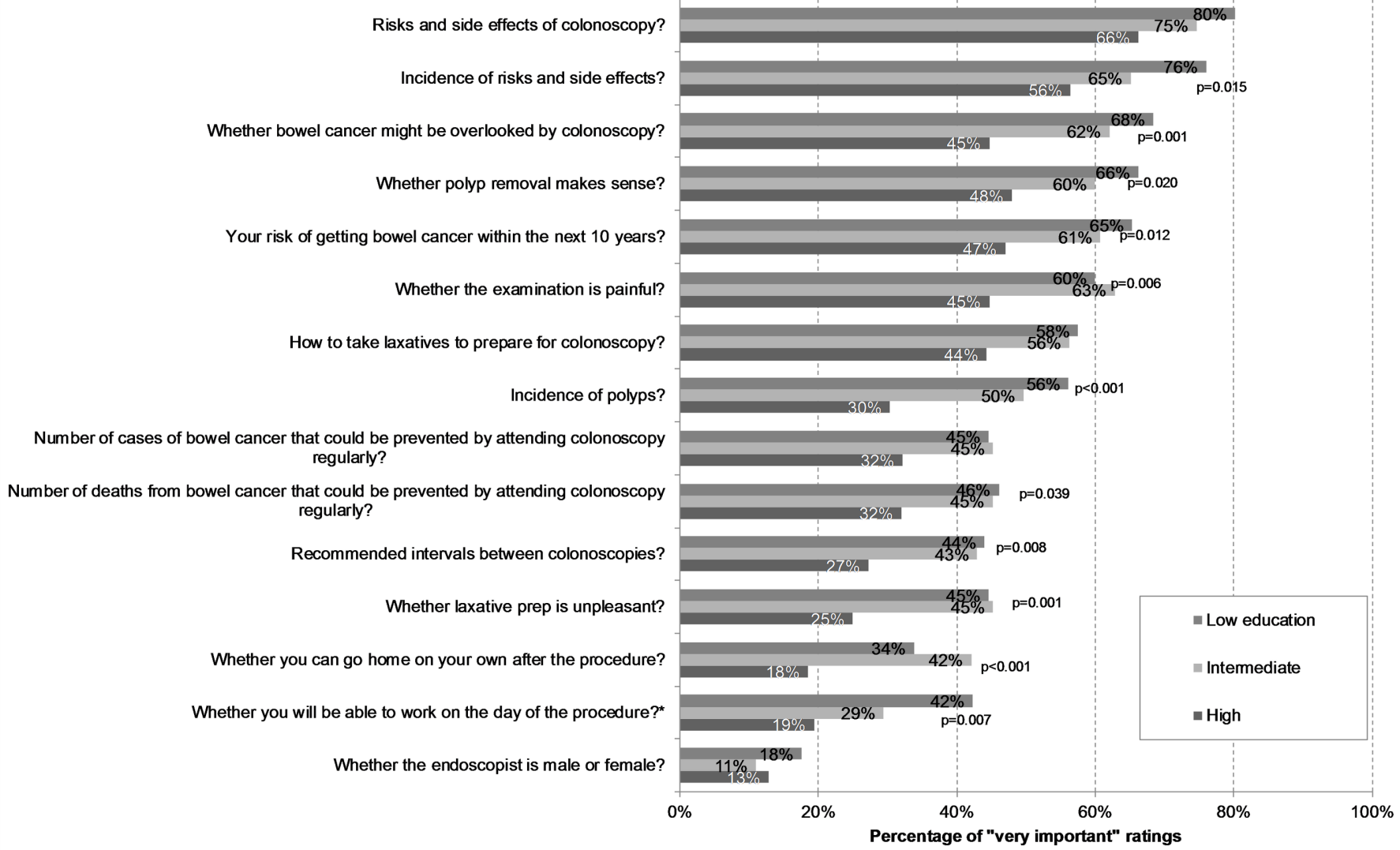

Figure 4 Importance of key information about screening colonoscopy by educational level ( $\mathrm{n}=346-357)$. ${ }^{*}$ Responses from employed persons only $(n=278)$.

While information on the risks and side effects of screening was most frequently rated as very important, roughly a quarter of the respondents rated information on screening benefits as unimportant. The ratings differed by sex and education level. Women regarded most of the items as being very important more often, especially information on risks (eg, pain) and practical aspects of the procedure. Generally, less educated subjects rated nearly all of the information as being important more frequently, but a significantly higher percentage of people with a low educational level living alone rated information on screening risks as being less important.

\section{Information on the risks and benefits}

One of the main pillars of informed decision making is information on risks. ${ }^{56}$ The predominant focus on information about the potential risks and side effects of colonoscopy screening underlines the fact that people want to make informed decisions. However, this information is not regularly provided, as a systematic evaluation of the available print information on CRC screening in Germany showed: nearly one-third of all information materials investigated failed to mention basic information on potential harms associated with CRC screening. ${ }^{18}$ A survey of US adults aged 50 years and older yielded similar results: almost $30 \%$ of women and men surveyed said that their healthcare providers did not discuss any of the drawbacks of CRC screening with them, while over 95\% said that they had discussed the advantages. ${ }^{19}$ Further effort is needed to empower patients to make informed decisions by providing health communication with appropriate information on all relevant factors, including the risks of CRC screening. The consumers seem to agree. ${ }^{20}$

In contrast, a minority of subjects appreciated key information regarding benefits of screening colonoscopy. In our study, $26 \%$ of subjects actually perceived the reduction in incidence and mortality of CRC as unimportant. Several factors may be responsible for this. First, the benefits of a screening examination are assumed as obvious or overestimated by many people. ${ }^{21-23}$ Second, consumers might assume that all examinations covered by their health insurance companies are beneficial anyway. Third, the items on the reduction in incidences and mortality of CRC were presented in quantitative terms describing the absolute risk reduction, that is, 'the number of bowel cancer-related deaths that could be prevented'. Subjects with lower numeracy skills may perceive quantitative information as less important because of their inability to understand these statistics. ${ }^{24}$ Fourth, goal framing might be present due to the use of a gain message (eg, the number of deaths that could be prevented by regular screening) instead of a loss message (eg, the number of deaths that will occur due to failure to attend screening). 


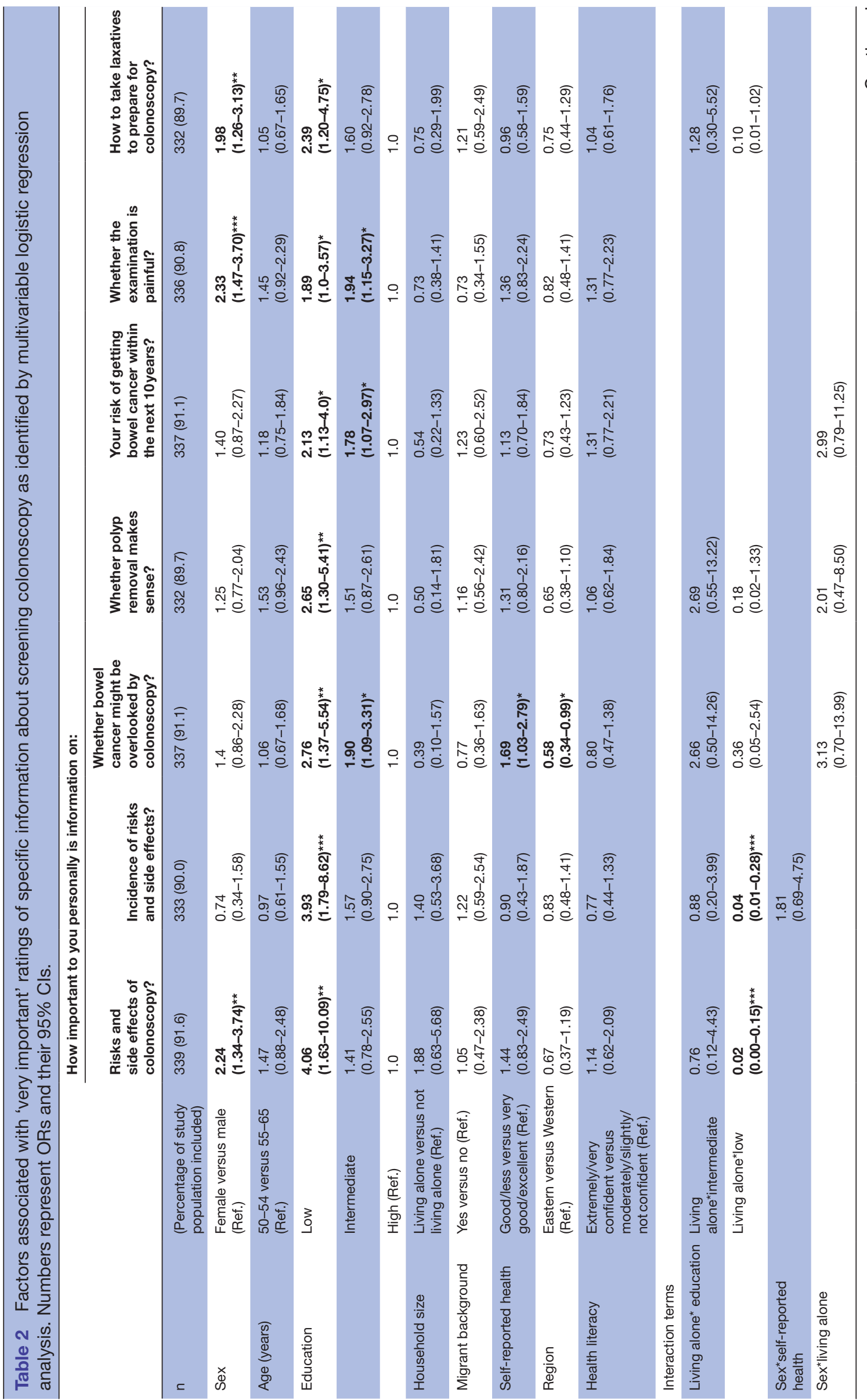

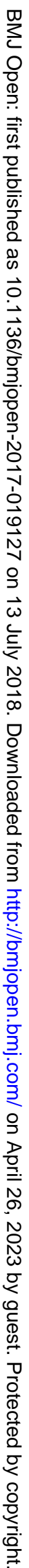




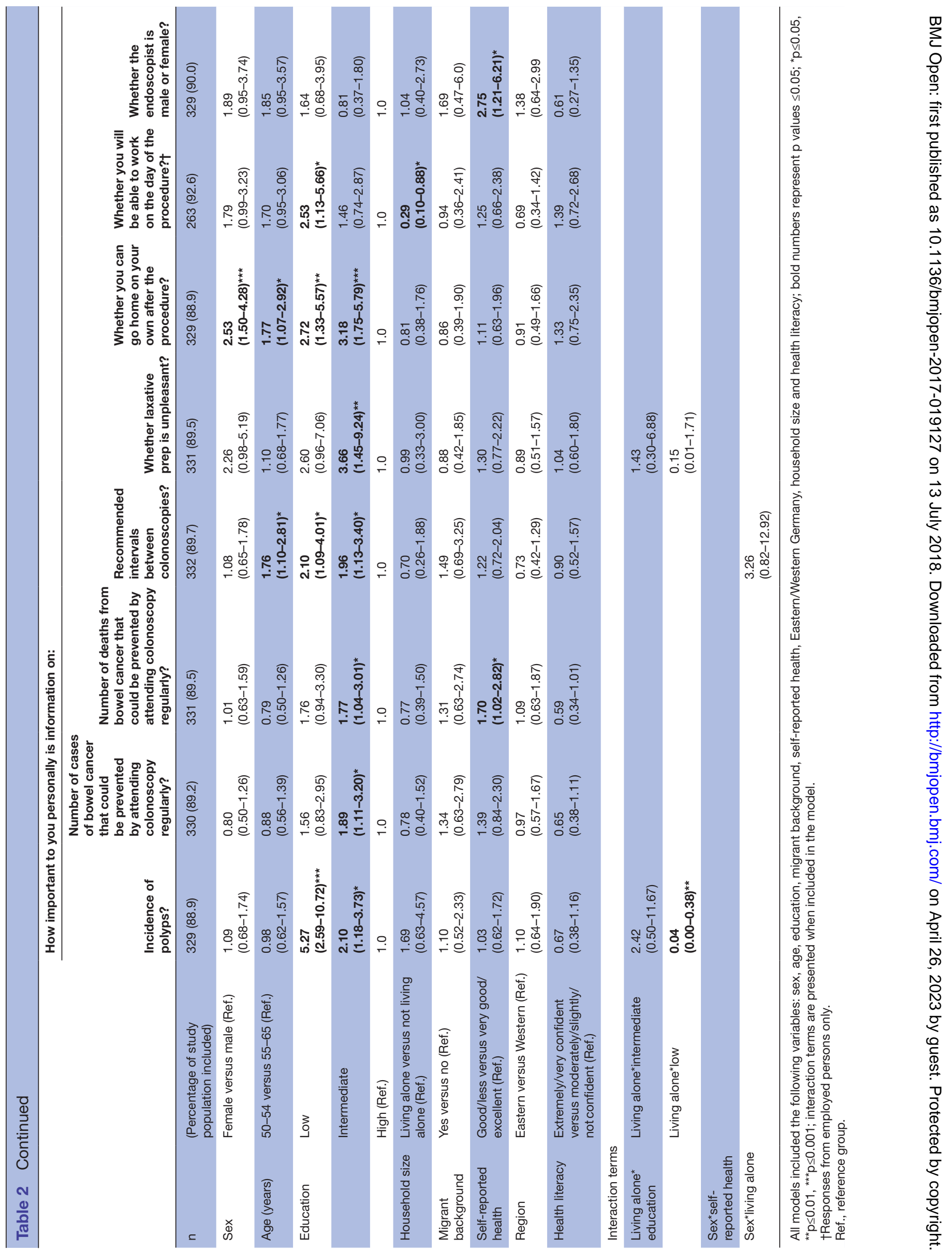




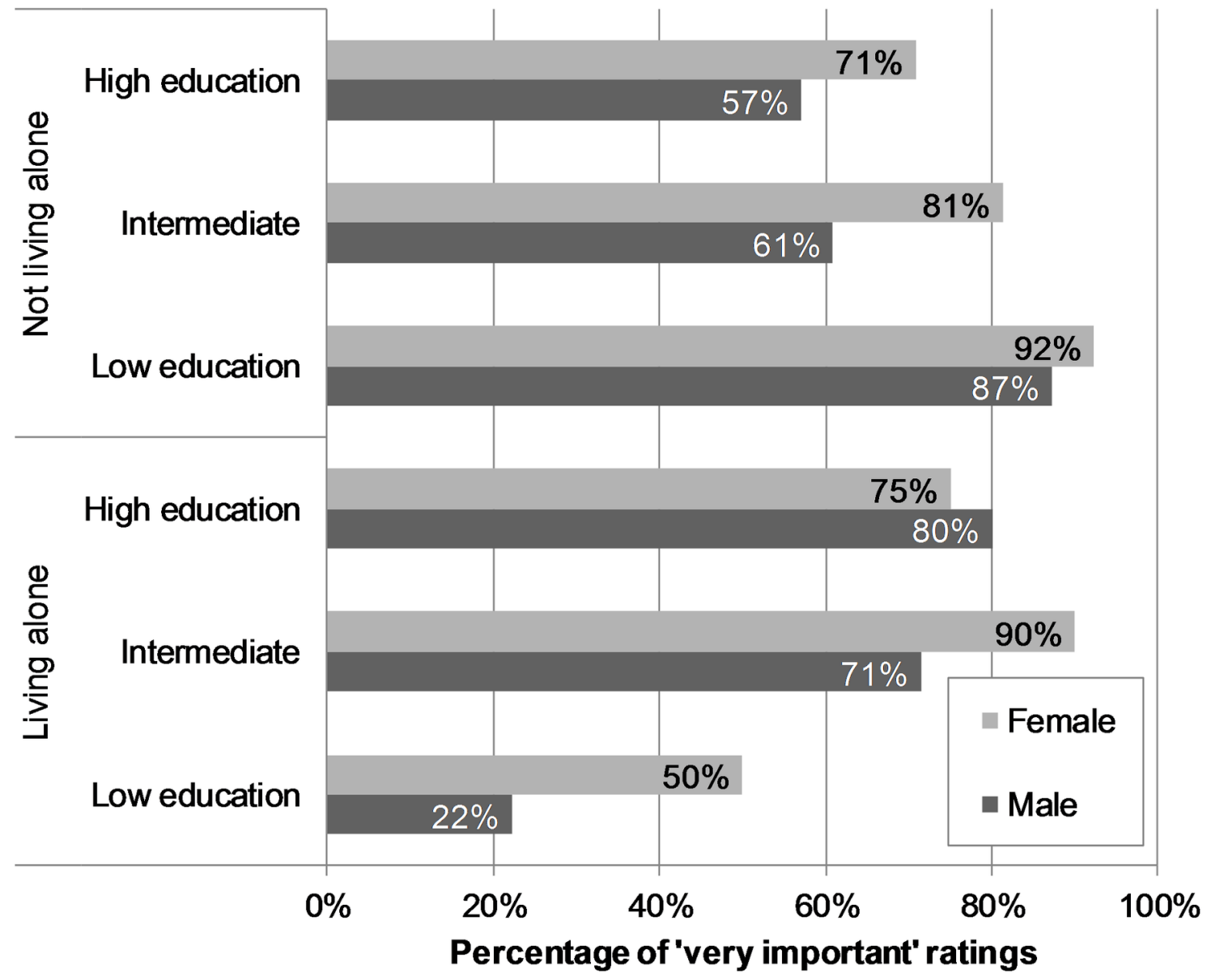

Figure 5 Information on risks and side effects of colonoscopy: percentage of 'very important' ratings stratified by sex, educational level and household size $(n=353)$.

Loss messages are shown to be associated with a more positive perception of the effectiveness of a procedure. ${ }^{25}$ Therefore, the framing of information on the benefits of screening colonoscopy as a loss message might have resulted in a higher rating of the importance of information on screening benefits.

\section{Differences in sex and educational levels}

In our study, women showed higher information needs than men on risks, pain, laxative use and going home independently afterwards. Similar results were found in a study using focus groups interviews in which the women demanded more information in terms of both quantity and detail, while men preferred little or no information on endoscopic procedures. ${ }^{26}$ These differences between women and men might be due to the use of different strategies to overcome their fears.

We detected significantly higher information needs in less educated groups. Similarly, a study on information needs in patients with cancer using a five-point scale to measure importance also showed that a low educational level is associated with higher information needs. ${ }^{27}$ Likewise, this might be due to a lower level of knowledge and understanding on CRC screening. However, in our study, health literacy was not associated with information needs while other studies showed a relation. ${ }^{22} 2829$ A reason for this could be that the screening question we used to explore health literacy was not of a sensitive nature within our study population.

In contrast to the finding of higher information needs in less educated groups, our results suggest that, as a group, subjects with low education level living alone are clearly less interested in information on the risks and side effects of screening colonoscopy. Apparently, they are not interested in making an informed decision or are unable to do so due to low health literacy. Living alone might serve as a surrogate for an increased risk of social isolation and low social support. Thus, this group is likely to be the most vulnerable group with the highest health risks. ${ }^{30}$ However, 
we could not ascertain the actual screening behaviour of this group based on the available data. Moreover, results on living alone must be interpreted with caution because of the low number of cases. Future research is needed to obtain deeper insights into the contrasting information needs people with low education level living alone, who may constitute an important risk group.

\section{Limitations}

This study has some limitations, which are discussed below. First, while colonoscopy is widely considered as the gold standard to diagnose CRC, only a few countries offer colonoscopy for primary screening. ${ }^{11}$ Most screening programmes use colonoscopy only after a positive stool test, in which case colonoscopy is a diagnostic and not a screening procedure, as individuals with a positive stool test cannot be considered asymptomatic and have an increased CRC risk. Therefore, our results are not generalisable to this situation as our study refers to colonoscopy for primary screening. Second, the study population consisted solely of persons with Barmer GEK statutory health insurance, who might not be representative of the German population at large. However, we believe that this can be assumed to a great extent for two reasons: (A) $85 \%$ of Germans are covered by statutory health insurance (and most of the remaining by private insurance), and (B) since 1996, German residents are largely free to choose between health insurance companies, all of them offer very similar benefits and charge similar premiums. However, as a German questionnaire was used, subjects with minor German language skills may be under-represented. Third, analysis was restricted to the subgroup of colonoscopy-naïve subjects, because evidence-based information on colonoscopy for primary screening mainly addresses people who have not yet experienced this procedure. ${ }^{31}$ By selecting this subgroup, the validity of the results may be limited. However, this subgroup analysis was derived from an a priori research question that addressed colonoscopy-naive subjects. Therefore, multiple testing is not a predominant issue. Fourth, as the insurance data did not provide the lifetime colonoscopy status, our final study population was based on self-reported statuses, which made it impossible to identify the denominator in the initial sample of our study population. Without a precise denominator, the response rate and potential differential response remained unknown. Using the non-responder analysis instead as a substitute, we cannot exclude a substantial selection bias. However, the proportion of participation is not necessarily associated with the magnitude of bias. ${ }^{32}$ Moreover, a response bias is mainly restricted to the prevalence of exposures or outcomes, while associations are only affected, if the response is both associated with the exposure and outcome. The risk of misclassification of the self-reported colonoscopy status (eg, confusion with other endoscopic procedures) was considered low, as the questionnaire included a description of the procedure and knowledge about colonoscopy is common because screening colonoscopies were introduced more than 10 years ago. Fifth, the fact that subjects rated most items as either 'very' or 'moderately important' and almost never as 'very unimportant' indicates that the four-point scale of importance may have resulted in a ceiling effect. Nevertheless, all of the response options were used by the respondents, and the fact that most respondents considered the sex of the endoscopist to be relatively unimportant shows that they were able to discriminate across the spectrum of different types of information. In further analyses, the responses were dichotomised to 'very important' versus 'other'. Focusing on the 'very important' ratings allowed us to detect relevant differences. Sixth, we did not include information on overdiagnosis as a potential harm. Although this is a huge problem in prostate cancer screening, there is probably little overdiagnosis associated with screening colonoscopy. ${ }^{33}$ Seventh, the models on the associated factors of the attributed importance of specific information on screening colonoscopy may suffer from residual confounding.

\section{Implications}

The findings of our study have several implications. As an informed choice requires knowledge about the absolute frequencies of the risks and benefits of screening, ${ }^{5-7}$ and one-quarter of respondents considered data on the numbers of prevented death as being unimportant, future information on screening colonoscopy should comprehensibly describe the benefits including quantitative information. A former evaluation of information materials on CRC screening had shown that benefits are often presented in general terms, not based specifically on colonoscopy, and without quantifying the associated risk reduction. ${ }^{18}$ However, numeracy skills are crucial to understanding quantitative information which, in turn, is essential to informed decision making. ${ }^{34}$ Pictographs are being used increasingly in patient decision aids on cancer screening in Germany. ${ }^{35}$ This may help to improve patient understanding of essentially quantitative messages in screening information. ${ }^{36-38}$

In light of the observed differences in information preferences between women and men, tailoring future information according to sex-specific needs may be warranted. Health information materials for women and men that differ in the sex-specific baseline risks of getting CRC are already available. ${ }^{39}{ }^{40}$ Further modifications according to the perceived information needs should be tested. Health information should also be adjusted to individuals with lower level education or literacy. The high demand of less educated people to become informed encourages further efforts to design evidence-based information materials that adequately inform this population. To date, several studies revealed that individuals with lower health literacy or educational levels show deficits in informed decision making. ${ }^{41-43}$ However, identifying these groups, for example, via screening questions, and then offering health information may not be practical or even stigmatising. Strategies to address educational and literacy 
inequalities may be implemented via self-selection and may include offering information in simple language, with a shorter extent of information, using different information channels like web-based information and videos and improving communication with health professionals. ${ }^{14445}$

Acknowledgements We would like to thank the Bertelsmann Stiftung and Barmer GEK for making this study possible. Special thanks also to the persons who took the time to do the pretests, and last but not least, we would like to thank the insurees who participated in this study.

Contributors All authors developed the conception and design of the study. MD and KK analysed and interpreted the data, and drafted the manuscript. All authors revised the work critically for intellectual content. All authors approved the final version of the manuscript and are accountable for all aspects of the work.

Funding Financial support for this study was provided in part by a grant from the Bertelsmann Foundation (non-profit organisation) und Barmer GEK (German health insurance company) for material costs and data entry services. The funding agreements ensured the authors independence in designing the study, interpreting the data and writing and publishing the report.

Competing interests None declared.

Patient consent Not required.

Ethics approval Ethics committee of Hannover Medical School.

Provenance and peer review Not commissioned; externally peer reviewed.

Data sharing statement № additional data are (currently) available.

Open access This is an open access article distributed in accordance with the Creative Commons Attribution Non Commercial (CC BY-NC 4.0) license, which permits others to distribute, remix, adapt, build upon this work non-commercially, and license their derivative works on different terms, provided the original work is properly cited, appropriate credit is given, any changes made indicated, and the use is non-commercial. See: http://creativecommons.org/licenses/by-nc/4.0/.

\section{REFERENCES}

1. Arnold M, Sierra MS, Laversanne M, et al. Global patterns and trends in colorectal cancer incidence and mortality. Gut 2017;66:1-9.

2. Brenner $\mathrm{H}$, Altenhofen $\mathrm{L}$, Stock $\mathrm{C}$, et al. Expected long-term impact of the German screening colonoscopy programme on colorectal cancer prevention: analyses based on 4,407,971 screening colonoscopies. Eur J Cancer 2015;51:1346-53.

3. Pox CP, Altenhofen L, Brenner $\mathrm{H}$, et al. Efficacy of a nationwide screening colonoscopy program for colorectal cancer. Gastroenterology 2012;142:1460-7.

4. Stock C, Ihle P, Sieg A, et al. Adverse events requiring hospitalization within 30 days after outpatient screening and nonscreening colonoscopies. Gastrointest Endosc 2013;77:419-29.

5. Bunge M, Mühlhauser I, Steckelberg A. What constitutes evidencebased patient information? Overview of discussed criteria. Patient Educ Couns 2010;78:316-28.

6. Marteau TM, Dormandy E, Michie S. A measure of informed choice. Health Expect 2001;4:99-108.

7. Trikalinos TA, Wieland LS, Adam GP, et al. Decision Aids for Cancer Screening and Treatment. Comparative Effectiveness Review No. 145. Rockville: Agency for Healthcare Research and Quality, 2014

8. Austoker J, Giordano L, Hewitson P, et al. European guidelines for quality assurance in colorectal cancer screening and diagnosis. First Edition-Communication. Endoscopy 2012;44:SE164-85.

9. Arbyn M, Anttila A, Jordan J, et al. European Guidelines for Quality Assurance in Cervical Cancer Screening. Second edition-summary document. Ann Oncol 2010;21:448-58.

10. Bunderegierung. Gesetz zur Weiterentwicklung der Krebsfrüherkennung und zur Qualitätssicherung durch klinische Krebsregister. Krebsfrüherkennungs- und -registergesetz - KFRG. Bundesgesetzblatt 2013;16:617-23.

11. Altobelli E, Lattanzi A, Paduano R, et al. Colorectal cancer prevention in Europe: burden of disease and status of screening programs. Prev Med 2014;62:132-41.

12. Elwyn G, Lloyd A, Joseph-Williams N, et al. Option Grids: shared decision making made easier. Patient Educ Couns 2013;90:207-12.
13. Brenner $\mathrm{H}$, Stock $\mathrm{C}$, Hoffmeister M. Effect of screening sigmoidoscopy and screening colonoscopy on colorectal cancer incidence and mortality: systematic review and meta-analysis of randomised controlled trials and observational studies. BMJ 2014;348:g2467.

14. Smith SK, Trevena L, Barratt $A$, et al. Development and preliminary evaluation of a bowel cancer screening decision aid for adults with lower literacy. Patient Educ Couns 2009;75:358-67.

15. Dreier M, Borutta B, Seidel G, et al. Development of a comprehensive list of criteria for evaluating consumer education materials on colorectal cancer screening. BMC Public Health 2013;13:843.

16. Schenk L, Bau A-M, Borde T, et al. Mindestindikatorensatz zur Erfassung des Migrationsstatus. Bundesgesundheitsblatt Gesundheitsforschung Gesundheitsschutz 2006;49:853-60.

17. Chew LD, Griffin JM, Partin MR, et al. Validation of screening questions for limited health literacy in a large VA outpatient population. J Gen Intern Med 2008;23:561-6.

18. Dreier M, Borutta B, Seidel G, et al. Communicating the benefits and harms of colorectal cancer screening needed for an informed choice: a systematic evaluation of leaflets and booklets. PLoS One 2014;9:e107575-11.

19. Hoffman RM, Lewis CL, Pignone MP, et al. Decision-Making Processes for Breast, Colorectal, and Prostate Cancer Screening: The DECISIONS Survey. Medical Decision Making 2010;30:53-64.

20. Biesecker BB, Schwartz MD, Marteau TM. Enhancing informed choice to undergo health screening: a systematic review. $A m \mathrm{~J}$ Health Behav 2013;37:351-9.

21. Mazor KM, Calvi J, Cowan R, et al. Media messages about cancer: what do people understand? J Health Commun 2010;15(Suppl 2):126-45.

22. Hudson B, Zarifeh A, Young L, et al. Patients' expectations of screening and preventive treatments. Ann Fam Med 2012;10:495-502.

23. Hoffmann TC, Del Mar C. Patients' expectations of the benefits and harms of treatments, screening, and tests: a systematic review. JAMA Intern Med 2015;175:274-86.

24. Smith SG, Wolf MS, von Wagner C. Socioeconomic status, statistical confidence, and patient-provider communication: an analysis of the Health Information National Trends Survey (HINTS 2007). J Health Commun 2010;15(Suppl 3):169-85.

25. Akl EA, Oxman $A D$, Herrin J, et al. Framing of health information messages. Cochrane Database Syst Rev 2011;12:1-81.

26. Friedemann-Sánchez G, Griffin JM, Partin MR. Gender differences in colorectal cancer screening barriers and information needs. Health Expect 2007;10:148-60.

27. Matsuyama RK, Wilson-Genderson M, Kuhn L, et al. Education level, not health literacy, associated with information needs for patients with cancer. Patient Educ Couns 2011;85:e229-e236.

28. Schmidt A, Kowalski C, Pfaff $\mathrm{H}$, et al. The Influence of Health Literacy on Information Needs Among Women Newly Diagnosed With Breast Cancer, With Special Reference to Employment Status. J Health Commun 2015:20:1177-84.

29. Ojinnaka CO, Bolin JN, McClellan DA, et al. The role of health literacy and communication habits on previous colorectal cancer screening among low-income and uninsured patients. Prev Med Rep 2015;2:158-63.

30. Courtin E, Knapp M, isolation S. loneliness and health in old age: a scoping review. Health Soc Care Community 2017:1-14.

31. van Dam L, Hol L, de Bekker-Grob EW, et al. What determines individuals' preferences for colorectal cancer screening programmes? A discrete choice experiment. Eur J Cancer 2010;46:150-9.

32. Stang $\mathrm{A}$, Jöckel $\mathrm{KH}$. Studies with low response proportions may be less biased than studies with high response proportions. Am J Epidemiol 2004;159:204-10.

33. Brenner H, Altenhofen L, Stock C, et al. Prevention, early detection, and overdiagnosis of colorectal cancer within 10 years of screening colonoscopy in Germany. Clin Gastroenterol Hepatol 2015;13:717-23.

34. Ciampa PJ, Osborn CY, Peterson NB, et al. Patient numeracy, perceptions of provider communication, and colorectal cancer screening utilization. J Health Commun 2010;15(Suppl 3):157-68.

35. The Federal Joint Committee. Informationen zum Mammographiescreening. Programm zur Früherkennung von Brustkrebs für Frauen zwischen 50 und 69 Jahren. Berlin: Gemeinsamer Bundesausschuss. 2015. https://www.g-ba.de/ downloads/17-98-2232/2015-11-13_Merkblatt-Mammographie_bf. pdf

36. Galesic M, Garcia-Retamero R, Gigerenzer G. Using icon arrays to communicate medical risks: overcoming low numeracy. Health Psychol 2009;28:210-6. 
37. Hess R, Visschers VHM, Siegrist M. Risk communication with pictographs: The role of numeracy and graph processing. Judgment and Decision Making 2011;6:263-74.

38. Zikmund-Fisher BJ, Fagerlin A, Ubel PA. A demonstration of "less can be more" in risk graphics. Med Decis Making 2010;30:661-71.

39. informedhealth.org. Colorectal cancer: Colonoscopy: Information for women. Published by the Institute for Quality and Efficiency in Healthcare. https://www.informedhealth.org/colorectal-cancer.2069. en.pdf?all_backgrounds $=0$

40. informedhealth.org. Colorectal cancer: Colonoscopy: Information for men. Published by the Institute for Quality and Efficiency in Healthcare. https://www.informedhealth.org/colorectal-cancer.2069. en.pdf?all_backgrounds $=0$

41. Fransen MP, Dekker E, Timmermans DRM, et al. Accessibility of standardized information of a national colorectal cancer screening program for low health literate screening invitees: A mixed method study. Patient Educ Couns 2017:100.

42. Essink-Bot ML, Dekker E, Timmermans DR, et al. Knowledge and Informed Decision-Making about Population-Based Colorectal Cancer Screening Participation in Groups with Low and Adequate Health Literacy. Gastroenterol Res Pract 2016;2016:1-8.

43. Peterson NB, Dwyer KA, Mulvaney SA, et al. The influence of health literacy on colorectal cancer screening knowledge, beliefs and behavior. J Natl Med Assoc 2007;99:1105-12.

44. Kobayashi LC, Wardle $\mathrm{J}$, von Wagner C. Limited health literacy is a barrier to colorectal cancer screening in England: evidence from the English Longitudinal Study of Ageing. Prev Med 2014;61:100-5.

45. Katz ML, Heaner S, Reiter P, et al. Development of an educational video to improve patient knowledge and communication with their healthcare providers about colorectal cancer screening. Am J Health Educ 2009;40:220-8. 